\title{
Meeting the Challenges in Oncology Care Management During the SARS-Cov-2 Pandemic: A Retrospective Analysis
}

\section{Marika Rasschaert ( $\nabla$ marika.rasschaert@uza.be)}

Multidisciplinary Oncological Center Antwerp, MOCA, University Hospital Antwerp

Pieterjan Vanclooster

Multidisciplinary Oncological Center Antwerp, MOCA, University Hospital Antwerp

\section{Laura Depauw}

Antwerp University Hospital

\section{Tim Mertens}

Antwerp University Hospital

\section{Ella Roelant}

University of Antwerp (UA)

\section{Elke Coenen}

Antwerp University Hospital

\section{Sebastien Anguille}

Antwerp University Hospital

\section{Annelies Janssens}

Multidisciplinary Oncological Center Antwerp, MOCA, University Hospital Antwerp

\section{Peter Dam}

Antwerp University Hospital

\section{Marc Peeters}

Antwerp University Hospital Antwerp

\section{Research Article}

Keywords: SARS-Cov-2, COVID-19, cancer care, telehealth, ehealth

Posted Date: March 31st, 2021

DOI: https://doi.org/10.21203/rs.3.rs-326353/v1

License: (1) (1) This work is licensed under a Creative Commons Attribution 4.0 International License.

Read Full License 


\section{Abstract}

Background: The SARS-CoV-2 pandemic has a far-reaching impact on healthcare. Cancer patients in particular were regarded as vulnerable and oncology departments drastically modified their Care systems and established new priorities. We evaluated the impact of SARS-CoV-2 on the activity of a single cancer center; and we studied patients' perspectives of the preventive institutional or governmental safety measures.

Methods: We performed a retrospective analysis of (i) Volumes of Oncological activities (2020 versus 2019), (ii) patients' perception rate of the preventive measures, (iii) patients' SARS-Cov-2 infections, clinical signs thereof and (iv) new diagnoses made during the SARS-CoV-2 pandemic.

Results: As compared with a similar timeframe in 2019 the overall activity in total numbers of outpatient chemotherapy administrations and specialist visits, based on weekly average of daily accesses was not statistically different; while inpatient admissions decreased for both medical oncology and thoracic oncology $(18 \%(p=0.0018)$ and $44 \%(p<0.0001)$ respectively). Cancer diagnosis plummeted $(34 \%)$, but no stage shift could be demonstrated.

Acceptance and adoption of hygienic measures was high, as measured by a targeted questionnaire administered to a sample of outpatients ( $>85 \%)$. However, only $46.2 \%$ of responding patients regarded telemedicine, although widely deployed, as an efficient surrogate to a consultation.

Thirty-three patients developed SARS-CoV-2, 27 were hospitalized and 11 died within this time frame. These infected patients were younger, current smokers and suffered more comorbidities.

Conclusions: This retrospective cohort analysis demonstrates that continuation of active cancer therapy and specialist visits is feasible and safe after implementation of population-wide, institutional and department specific safety measures. Substantial decreases in diagnosis of solid tumors were recorded. To manage the backlog of belated diagnoses, while providing continued state-of-the-art cancer care during this prolonged health crisis, we need policy interventions to adapt the health care system and allow telemedicine to fulfill a more prominent role.

\section{Introduction}

The severe acute respiratory syndrome Coronavirus 2 (SARS-CoV-2) is a novel enveloped RNA coronavirus. It belongs to the genus Betacoronaviridae, as does the SARS-CoV-1 (1) and MERS-CoV (2). The genome of the virus demonstrates $96 \%$ of concordance with the genome of a bat coronavirus suggesting its potential origin $(3,4)$. Available evidence suggests that the virus is predominantly transmitted between people through respiratory droplets and close contact, but there are also examples of transmissions between humans and animals. Several animals that have been in contact with infected humans, such as minks, dogs, domestic cats, lions and tigers, have tested positive for SARS-CoV-2 or a variant strain of the SARS-CoV-2. 
SARS-CoV-2, was first identified in humans in December 2019. As a viral pneumonia, it has affected more than 48 million people causing over 1.2 million deaths worldwide. (5) The speed with which SARS-CoV-2 spread globally has challenged the traditional health care delivery system and forced immediate change likely to last for a prolonged time. Initially it was presumed that Cancer patients especially were at higher risk for SARS-CoV-2 transmission and disease, because of the underlying disease, comorbid conditions or treatment related immune dysfunction. Early data from China seemed to confirm the higher infection rates (6) but were later contradicted by reports from other parts of the world $(7,8)$ and refined as the UKexperience demonstrated a differential susceptibility relative to tumor type.(9) Similar to patients without cancer, the severity or fatality rate in cancer patients is confounded by factors such as, age, gender, cardio-vascular morbidities, obesity, diabetes and even tumor type $(10,11,12,13)$. Still, when cancer patients suffer severe SARS-CoV-2, the in-hospital mortality rate is higher compared to non-oncology patients, particularly in patients with metastatic disease and patients with hematological cancers. $(14,15)$

The SARS-CoV-2 outbreak has challenged the Oncologic community and forced Oncology professionals to navigate effective cancer care with varying shortages of all resources from personal protective equipment, diagnostic test to practice capacities. In order to provide the safest and efficient care to all, guidelines were published by the major Oncologic Societies; all of which are based on broad consensus and expert peer review $(16,17,18,19,20)$

As community infection rates and risk of transmission rises again these guidelines fare well with a comparison to real world experience.

We report in this single center cohort analysis the actual organizational changes implemented during the first peak of the SARS-CoV-2 pandemic, the changes in Oncologic care activities and diagnoses. In addition, we evaluated the patients' perception of the adopted measures and finally describe the SARSCoV-2 prevalence and co-morbidity in a cohort of cancer patients treated at a tertiary care hospital in Belgium.

\section{Material And Methods}

\section{Study Design, Data source and collection:}

We report a retrospective analysis of the clinical activity at the Antwerp University Hospital Cancer Center (MOCA) from March 17th to August 28th (week 8 until 34), and compared these data to the data of the same period in 2019.

We evaluated the effect of SARS-CoV-2 preventive measures on volumes of oncological activity by tracking the 1) number of consultations, the 2) number of outpatient treatments, 3) hospital admissions (pre-planned and not) and finally 4) the number of new Cancer diagnoses presented to the multidisciplinary oncology boards. (supplementary methods). 
All Cancer patients with a laboratory confirmed SARS-CoV-2 infection, both out- and inpatients at the Antwerp University Hospital were identified by reviewing medical charts and by screening for patients with positive Nasopharyngeal PCR-test from March 16th to August 7th. The clinical data such as patient demographics, comorbidities (including history of Cancer) and clinical presentation were retrieved from electronic medical records after anonymization.

The clinical data were compared to a population based national data set obtained by the Belgian public health institute (Sciensano) and published in literature. This data set concerns 13594 confirmed SARSCoV-2 hospitalized patients ( 1187 with a solid cancer), and were retrieved by Sciensano, on 24th of May 2020. (15)

\section{Patient-reported perception of organizational measures:}

To assess patients' perception of risks, their fears and the acceptance of protective/organizational measures, anonymous questionnaires (supplementary methods), approved by the Antwerp University Hospital psycho-oncology service, were administered at triage to all patients accessing our outpatient facilities over a 28-day period; questionnaires were returned on a voluntary basis.

\section{Statistical analysis}

Qualitative variables were presented with the observed numbers and percentages. For oncological activity volumes, 27 weekly average and total numbers +/- standard deviations were reported for weeks 8 until 35 of 2019 and 2020. Variations and differences in average activity volumes between the two periods were compared. Normality per group was tested with a Kolmogorov-Smirnov test and if normality was acceptable per group an independent samples t-test was used, if not a Mann Whitney test. The Levene's test evaluated if equal variances could be assumed, if not a Welch T-test was used.

The answers to relevant Questionnaire items are reported as percentages. When evaluating cancer diagnosis made during a similar period in 2019 as in 2020 numbers were described for 4 solid tumor types and per type the distribution of the stages between 2019 and 2020 was compared using a Chisquare test or Fisher's exact test as appropriate.

The clinical characteristics of SARS-CoV-2 infected patients were compared to a national data set(15) using a Chi-square test for the categorical variables and a Fisher's exact test if more than $20 \%$ of the expected values were lower than 5 . The corresponding odds ratio with $95 \%$ confidence interval was also calculated. For the age as continuous variable the Welch T-test was used. The statistical analysis was done using SPSS version 21, non-parametric confidence interval for odds ratio was computed in R-3.5.2 for windows.

\section{Results}

SARS-CoV-2 related events and organizational protective measures. 
The first Belgian SARS-CoV-2 infected patient was diagnosed on February Third 2020, after his return flight from China. On February $29^{\text {th }}$ the first patient was hospitalized and treated at the Antwerp University hospital; from that point onwards, health measures were issued such as issuing necessary protective shielding or FFP2 masks, regulating access to the institution and work-related travel. Governmental restrictions ("Lock down rules") to prevent the spread of SARS-CoV-2 in Belgium, were issued on March $13^{\text {th }} 2020$. The Antwerp University Hospital Cancer Center expanded on these measures to further insure safe cancer care. Follow up visits were delayed and rationalized according to expert based guidelines. (17) Telehealth, both tele-consultations and tele-monitoring was implemented and expanded upon. Telemonitoring used an adapted form of a standardized toxicity reporting system to also evaluate COVID-19 related symptoms. This clinician supervised e-tool was proposed to all outpatients receiving active treatment. (additional data) In addition, a remote blood draw one day prior to the outpatient treatment shortened their stay at the oncology ward. Finally, a routine SARS-CoV-2 saliva testing was performed every fourth night (as soon as available). (Table 1)

Table 1: Specific preventive measures in Health Care and specifically Cancer Care Proposed by different instances: Governmental, European association and Local. 


\begin{tabular}{|c|c|c|c|}
\hline & Belgian MoH / Sciensano & ESMO (21) & $\begin{array}{l}\text { Antwerp University } \\
\text { Hospital }\end{array}$ \\
\hline Triage & No reference to triage & $\begin{array}{l}\text { No access until evaluation } \\
\text { by healthcare professional } \\
\text { of COVID-19 related } \\
\text { symptoms. }\end{array}$ & $\begin{array}{l}\text { Physical triage at } \\
\text { entrance of hospital } \\
\text { "Previous day" telephone } \\
\text { triage or e-questionnaire } \\
\text { concerning COVID-19 } \\
\text { related symptoms. } \\
\text { Attribution of color- } \\
\text { coded entrance. }\end{array}$ \\
\hline $\begin{array}{l}\text { Active } \\
\text { Cancer } \\
\text { Care }\end{array}$ & $\begin{array}{l}\text { Local Health authorities and } \\
\text { each hospital should identify } \\
\text { urgent from non-urgent care } \\
\text { and guarantee safe } \\
\text { administration of essential } \\
\text { treatments }\end{array}$ & $\begin{array}{l}\text { Prioritize adjuvant therapies } \\
\text { Discuss benefits and risks } \\
\text { of present cancer therapy, } \\
\text { treatment setting, disease } \\
\text { prognosis, patients } \\
\text { comorbidities and patients } \\
\text { preferences. } \\
\text { Reduce number of visits or } \\
\text { re-evaluate treatment } \\
\text { schedules }\end{array}$ & $\begin{array}{l}\text { No interruption or delay } \\
\text { of active cancer care } \\
\text { (both curative and } \\
\text { palliative intent) } \\
\text { Color coded entrance } \\
\text { and patient flow } \\
\text { E-registry of toxicity and } \\
\text { COVID- } 19 \text { related } \\
\text { symptoms. } \\
\text { "previous day" remote } \\
\text { blood test organized in } \\
\text { concert with care center. } \\
\text { Saliva test / every } 14 \\
\text { days. } \\
\text { Pre-validation of Cancer } \\
\text { treatment } \\
\text { Shortening of "chair } \\
\text { time" }\end{array}$ \\
\hline $\begin{array}{l}\text { Follow } \\
\text { up }\end{array}$ & $\begin{array}{l}\text { Post pone where possible } \\
\text { and in accordance with } \\
\text { specialists. } \\
\text { Re-imbursement of } \\
\text { telephone consultation }\end{array}$ & $\begin{array}{l}\text { Tele health and Digital } \\
\text { health: tools for } \\
\text { consultations and } \\
\text { counseling should be } \\
\text { improved to support } \\
\text { patients remotely and meet } \\
\text { their needs. }\end{array}$ & $\begin{array}{l}\text { Non-urgent FU visits } \\
\text { suspended. Telephone } \\
\text { and e-mail contacts to } \\
\text { allow evaluation of lab } \\
\text { and imaging. } \\
\text { Visits following } \\
\text { diagnostic evaluation or } \\
\text { exams remain possible }\end{array}$ \\
\hline Caregiver & No reference to caregivers & No reference to caregivers & $\begin{array}{l}\text { Not for active treatment. } \\
\text { One caregiver allowed in } \\
\text { case of necessity, end of } \\
\text { life (inpatient) and } \\
\text { treatment-related } \\
\text { decisions. }\end{array}$ \\
\hline
\end{tabular}

$\mathrm{MoH}$ : Ministery of Health 
ESMO : European Society of Medical Oncology

Chair time: the amount of time a patient spends in the care of a health provider for examination or treatment.

\section{Overall volumes of Oncology activities}

Within the observation period between February $17^{\text {th }}$ to August $30^{\text {th }}$, we evaluated the volumes of clinical oncological activity and compared them to the activities from a similar period in 2019. During these first months in the pandemic local and regional public health authorities prioritized urgent help and considered cancer care as such. Within these parameters all ongoing systemic therapy was continued and new treatments were initiated following careful evaluation of necessity (Supplementary data file).

The number (2020: mean=12.8, 2019: mean=15.6) of in-patient admissions of Oncology patients diminished with $18 \%$ ( $p=0.018$ using weekly averages), while outpatient therapies (2020: mean=117.1, 2019: mean=117) remained relatively similar. The shift form in-hospital treatment to outpatient therapy was even more pronounced for thoracic oncology patients, as demonstrated by a significant increase in outpatient therapy (2020: mean $=18.4,2019$ : mean $=16.2)(+14 \%, p=0.04)$. Considering Gynecological Oncological surgery, we did not demonstrate differences in in- nor outpatient admissions or consultations between 2019 and 2020. (Table 2)

Table 2: Changes in overall volumes of oncology activities during similar periods of 2019 and 2020 (eg weeks 8 to 35$)$. 


\begin{tabular}{|c|c|c|c|c|c|c|}
\hline & & 2019 & & 2020 & & \\
\hline & & Mean & SD & Mean & SD & $p$-value \\
\hline \multicolumn{7}{|l|}{ Overall } \\
\hline & Inpatient Admissions & 570.1 & 50.4 & 443.1 & 121.2 & $<0.0001^{\dagger}$ \\
\hline & $\begin{array}{l}\text { Outpatient } \\
\text { Admissions }\end{array}$ & 979.5 & 92.5 & 832.1 & 207.5 & $0.009^{*}$ \\
\hline & Consultations & 10162.3 & 1171 & 7652.8 & 2719 & $0.0002^{*}$ \\
\hline \multicolumn{7}{|l|}{ Oncology } \\
\hline & Inpatient & 15.6 & 4 & 12.8 & 3.5 & $0.018^{*}$ \\
\hline & Admissions & & & & & \\
\hline & $\begin{array}{l}\text { Outpatient } \\
\text { Admissions }\end{array}$ & 117 & 12.6 & 117.1 & 9 & $0.961 \S$ \\
\hline & Consultations & 148.7 & 16 & 142 & 25.8 & $0.252^{\dagger}$ \\
\hline \multicolumn{7}{|l|}{$\begin{array}{l}\text { Gynecological } \\
\text { Oncology }\end{array}$} \\
\hline & Inpatient & 7 & 3.1 & 6.9 & 3.4 & $0.867 \S$ \\
\hline & Admissions & & & & & \\
\hline & $\begin{array}{l}\text { Outpatient } \\
\text { Admissions }\end{array}$ & 5.6 & 2.6 & 4.1 & 3.4 & $0.083^{\S}$ \\
\hline & Consultations & 97.9 & 22.2 & 90.4 & 27.4 & $0.275^{\S}$ \\
\hline \multicolumn{7}{|l|}{ Thoracic Oncology } \\
\hline & Inpatient & 4.8 & 1.5 & 2.7 & 1.6 & $<0.0001^{*}$ \\
\hline & Admissions & & & & & \\
\hline & $\begin{array}{l}\text { Outpatient } \\
\text { Admissions }\end{array}$ & 16.2 & 4 & 18.4 & 3.7 & $0.040 \S$ \\
\hline & Consultations & 41 & 5.2 & 41 & 8.2 & $0.621^{*}$ \\
\hline
\end{tabular}

Weekly numbers were evaluated. Overall volumes refer to all disciplines at the Antwerp University Hospital. Oncology refers to Cancer care for solid tumors other than Thoracic Oncology. Gynecological oncology refers to surgical interventions / treatment for gynecologic malignancies.

SD : Standard Deviation 
${ }^{\dagger}$ Welch T-test

*MannWhitney test

SIndependent samples T-test

In hospital consultations with Oncology Specialists did not demonstrate statistical meaningful differences between 2019 and 2020 (Oncology: mean=148.7 vs mean=142 respectively; $p=0.252$ ).

\section{Diagnoses}

We retrospectively evaluated all new cancer diagnosis made at the Antwerp University Hospital Cancer Center during the period from February to July 2019 and 2020, for which a registration to the National Cancer Registry was made. The overall incidence of solid tumor plummeted with 34\%. (818 and 1243 incidences in 2019 and 2020 respectively). In order to evaluate stage migration because of delayed presentation we evaluated 4 major solid tumor types: breast, colorectal, lung and prostate cancer. All of which were profoundly less frequently diagnosed in 2020 (136, 43, 106 and 48) compared to 2019 (210, 59, 120 and 86). There was no statistical difference when evaluating the 2019 and 2020 cohort per tumor type and stage. (E.g. breast $(p=0.995), \operatorname{CRC}(p=0.152)$, lung $(p=0.474)$ and prostate $(p=0.535))$.

Questionnaire on the knowledge about and acceptance of risk mitigating.protective measures.

We send out a questionnaire in a cohort of outpatients $(n=119)$, the questions regarded organization and implementation of the Corona virus disease 2019 (COVID-19) protective measures at the hospital and Oncology Clinic; the acceptance thereof by cancer patients and anxiety concerning infection risk regardless of these measures. The demographics of the 119 responders can be reviewed in

\section{supplementary data file.}

A majority of patients were knowledgeable about the protective measures (88\%), most declared to have received this information at the entrance of the hospital (billboards) or subsequently at the triage gate following the entrance of the hospital (69 and 7.6\%).

Apprehension for waiting rooms or other hospital facilities was little and patients felt safe $73.1 \%$ and $79.8 \%$ respectively. Contrary and perhaps as a consequence, patients were somewhat reluctant to regard ehealth / or phone-based consultations as a valid surrogate. (46.2\% thought this to be an alternative and $34.5 \%$ only quite so).

We registered a broad appreciation of the risk mitigating strategies (68.9\% of respondents high and $25.2 \%$ quite high), however slight differences according to specific measures were noted. Wearing a face mask was well accepted by $79.0 \%(n=94 / 119)$ of patients and isolation within a "domestic cluster" (=a cluster of all people residing under the same roof) or Self - Quarantine (in case of high-risk contacts) demonstrated feasible for $63.9 \%(n=76 / 119)$ and $60.5 \%(n=72 / 119)$; Maintaining or restricting to a small social cluster proved less manageable and was appreciated by merely 49.6\% $(n=59 / 119)$. 
46.2\% ( $n=55 / 119)$ of Cancer patients claimed to be knowledgeable about the relative interaction of comorbidities and SARS-CoV-2; and 38.7\% $(n=46 / 119)$ of patients answered that they were afraid (or quite afraid) to receiving chemotherapy, because of a higher risk of transmission with the SARS-CoV-2 virus. (FIG 1.)

\section{SARS-CoV-2 and clinical presentation in Cancer patients}

On August $11^{\text {th }}$ we retrospectively identified 37 in-and out-hospital Cancer patients with a laboratory confirmed diagnosis of SARS-CoV-2 infection, at the Antwerp University Hospital. Clinical data of 33 of these patients were evaluated, we excluded 4 because no previous contact was retrieved and no clinical data was evaluable in the electronic patient file.

Twenty-seven patients out of thirty-three were hospitalized after SARS-CoV-2 infection of which one was treated in the intensive care unit. Eleven patients died. Our data set described cancer patients whom were younger and predominantly male compared to the national data set of non-cancer patients. We demonstrated more comorbidities, (number/per patient: $45.5 \%$ had $\geqq 3$ comorbidities $(p=0.029)$ ); especially obesity $(31.3 \%, p<0.001)$, hematological cancer $(18.2 \%, p<0.0001)$ and immunosuppressive disorders $(57.6 \%, p<0.0001)$ were more frequent in our patient cohort. Confounding comorbidities such hypertension and cardiovascular diseases were as frequent in our data set as in the non-cancer patients. Cancer patients more often were current smokers $(30.3 \%, p<0.0001)$ and presented less likely with symptoms before hospitalization ( $57.6 \%$ vs $94.1 \%, p<0.0001)$. However, if symptoms occurred they remained similar to the non-cancer patients. (Table 3)

We made no analysis on SARS-CoV-2 related outcome due to the small number of SARS-CoV-2 positive Cancer patients.

Table 3: Characteristisc of SARS-Cov-2 infected patients. 


\begin{tabular}{|c|c|c|c|c|}
\hline & $\begin{array}{l}\text { Patients without } \\
\text { cancer }(n=12407)\end{array}$ & $\begin{array}{l}\text { Patients with solid } \\
\text { cancer }(n=33)\end{array}$ & $P$ value & OR $(95 \% \mathrm{Cl})$ \\
\hline \multicolumn{5}{|l|}{ Age in Years } \\
\hline Mean (SD) & $67.7(17.1)$ & $61.6(12.9)$ & $0.011^{\dagger}$ & \\
\hline Median (IQR) & 70 (55 to 82) & 62 (28 to 82 ) & & \\
\hline \multicolumn{5}{|l|}{$\begin{array}{l}\text { Age in Years - n } \\
(\%)\end{array}$} \\
\hline$<50$ & $1952(15.7)$ & $4(12.1)$ & $0.0005^{\S}$ & 1 \\
\hline $50-59$ & $2002(16.4)$ & $5(15.2)$ & & $\begin{array}{l}1.22 \\
{[0.26,6.15]^{\star}}\end{array}$ \\
\hline $60-69$ & 2139 (17.2) & $15(45.5)$ & & $\begin{array}{l}3.42 \\
{[1.09,14.18]^{\prime}}\end{array}$ \\
\hline $70-79$ & $2463(19.9)$ & $7(21.1)$ & & $\begin{array}{l}1.39 \\
{[0.35,6.47]^{*}}\end{array}$ \\
\hline $80-89$ & 2976 (19.9) & $2(6.1)$ & & $\begin{array}{l}0.33 \\
{[0.03,2.29]^{*}}\end{array}$ \\
\hline$\geqq 90$ & $875(7.1)$ & 0 & & $0[0,3 \cdot 39]^{\star}$ \\
\hline \multicolumn{5}{|l|}{ Gender - n (\%) } \\
\hline Female & $5777(46.9)$ & $11(33.3 \%)$ & $0.118 \S$ & 1 \\
\hline Male & $6529(53.1)$ & $22(66.7 \%)$ & & $\begin{array}{l}1.77 \\
{[0.86,3.65]^{\S}}\end{array}$ \\
\hline Missing & 101 & 0 & & \\
\hline \multicolumn{5}{|l|}{ Comorbidities - n (\%) } \\
\hline $\begin{array}{l}\text { Cardiovascular } \\
\text { disease }\end{array}$ & $4128(33.7)$ & $16(48.5)$ & $0.064 \S$ & $\begin{array}{l}0.53 \\
{[0.27,1.05]^{\S}}\end{array}$ \\
\hline Hypertension & 4931 (39.7) & $16(48.5)$ & $0.306 \S$ & $\begin{array}{l}0.70 \\
{[0.35,1.39]^{\S}}\end{array}$ \\
\hline Diabetes & $2705(21.8)$ & $4(12.1)$ & $0.178 \S$ & $\begin{array}{l}2.02 \\
{[0.71,5.75]^{\S}}\end{array}$ \\
\hline $\begin{array}{l}\text { Chronic Kidney } \\
\text { disease }\end{array}$ & $1548(12.5)$ & $3(9.1)$ & $0.792^{*}$ & $\begin{array}{l}1.43 \\
{[0.44,7.31]^{\star}}\end{array}$ \\
\hline Chronic lung disease & $1777(14.3)$ & $4(12.1)$ & $1^{*}$ & $\begin{array}{l}1.21 \\
{[0.42,4.75]^{*}}\end{array}$ \\
\hline
\end{tabular}




\begin{tabular}{|c|c|c|c|c|}
\hline $\begin{array}{l}\text { Chronic neurological } \\
\text { disease }\end{array}$ & $1099(8.9)$ & $2(6.1)$ & $0.765^{\star}$ & $\begin{array}{l}1.51 \\
{[0.38,13.01]^{*}}\end{array}$ \\
\hline Cognitive disorder & $1441(11.7)$ & $2(6.1)$ & $0.423^{*}$ & $\begin{array}{l}2.05 \\
{[0.52,17.68]^{*}}\end{array}$ \\
\hline $\begin{array}{l}\text { Immunosuppression } \\
\text { (incl HIV) }\end{array}$ & $254(2.1)$ & $19(57.6)$ & $<0.0001^{*}$ & $\begin{array}{l}0.02 \\
{[0.01,0.03]^{\star}}\end{array}$ \\
\hline $\begin{array}{l}\text { Haematological } \\
\text { cancer }\end{array}$ & 0 & $6(18.2)$ & $<0.0001^{*}$ & $\begin{array}{l}0 \\
{[0.00,0.002]^{*}}\end{array}$ \\
\hline Pregnancy & $102(0.8)$ & 0 & $1^{*}$ & $\operatorname{Inf}[0.07, \operatorname{lnf}]^{\star}$ \\
\hline Postpartum (<6weeks) & $15(0.1)$ & 0 & $1^{*}$ & $\operatorname{lnf}[0.01, \operatorname{lnf}]^{\star}$ \\
\hline Obesity & $822(10.4)$ & $10(31.3)$ & $0.001^{*}$ & $\begin{array}{l}0.26 \\
{[0.12,0.61]^{\star}}\end{array}$ \\
\hline Missing & 4533 & 1 & & \\
\hline No comorbidities & 3019 (24.3) & $3(9.1)$ & $0.041^{\S}$ & $\begin{array}{l}3.22 \\
{[0.98,10.54]^{\S}}\end{array}$ \\
\hline $\begin{array}{l}\text { Number of } \\
\text { comorbidities - n (\%) }\end{array}$ & & & $0.029 \S$ & \\
\hline 0 & 3019 (24.3) & $3(9.1)$ & & 1 \\
\hline 1 & $3518(28.4)$ & $9(27.3)$ & & $\begin{array}{l}2.57 \\
{[0.64,14.80]^{*}}\end{array}$ \\
\hline 2 & $2787(22.5)$ & $6(18.2)$ & & $\begin{array}{l}2.17 \\
{[0.46,13.40]^{*}}\end{array}$ \\
\hline »3 & $3083(24.9)$ & $15(45.5)$ & & $\begin{array}{l}4.90 \\
{[1.38,26.41]^{*}}\end{array}$ \\
\hline Current smoker - n (\%) & & & $<0.0001^{\S}$ & \\
\hline No & $5936(47.8)$ & $20(60.6)$ & & 1 \\
\hline Yes & $660(5.3)$ & $10(30.3)$ & & $\begin{array}{l}4.50 \\
{[1.87,10.11]^{\star}}\end{array}$ \\
\hline Unknown & $5811(46.8)$ & $3(9.1)$ & & $\begin{array}{l}0.15 \\
{[0.03,0.52]^{\star}}\end{array}$ \\
\hline $\begin{array}{l}\text { Influenza vaccine - n } \\
(\%)\end{array}$ & & & $0.231^{*}$ & \\
\hline No & $913(7.4)$ & 0 & & 1 \\
\hline Yes & $825(6.7)$ & $1(3)$ & & $\operatorname{Inf}[0.03, \operatorname{lnf}]^{\star}$ \\
\hline
\end{tabular}




\begin{tabular}{|c|c|c|c|c|}
\hline Unknown & $10669(86.0)$ & $32(97)$ & & $\operatorname{lnf}[0.70, \operatorname{lnf}]^{\star}$ \\
\hline $\begin{array}{l}\text { Timing of symptoms } \\
\text { onset }-n(\%)\end{array}$ & & & $<0.0001^{*}$ & \\
\hline $\begin{array}{l}\text { Before or day of } \\
\text { hospitalization }\end{array}$ & $11680(94.1)$ & 19 (57.6) & & 1 \\
\hline During hospitalization & $727(5.9)$ & $14(42.4)$ & & $\begin{array}{l}11.84 \\
{[5.47,25.01]^{\star}}\end{array}$ \\
\hline \multicolumn{5}{|l|}{$\begin{array}{l}\text { Symptoms at } \\
\text { presentation - n (\%) }\end{array}$} \\
\hline Systemic symptoms & $9120(73.5)$ & $22(66.7)$ & $0.374 \S$ & $\begin{array}{l}1.39 \\
{[0.67,2.86]^{\S}}\end{array}$ \\
\hline Respiratory symptoms & $9037(72.8)$ & $26(78.8)$ & $0.443 \S$ & $\begin{array}{l}0.72 \\
{[0.31,1.66]^{\S}}\end{array}$ \\
\hline $\begin{array}{l}\text { Gastrointestinal } \\
\text { symptoms }\end{array}$ & $2655(21.4)$ & $10(30.3)$ & $0.213 \S$ & $\begin{array}{l}0.63 \\
{[0.30,1.32]^{\S}}\end{array}$ \\
\hline $\begin{array}{l}\text { Neurological } \\
\text { symptoms }\end{array}$ & $2146(17.3)$ & $3(9.1)$ & $0.213 \S$ & $\begin{array}{l}2.09 \\
{[0.64,6.86]^{\S}}\end{array}$ \\
\hline Pain & $2740(22.1)$ & $7(21.2)$ & $0.904 \S$ & $\begin{array}{l}1.05 \\
{[0.46,2.43]^{\S}}\end{array}$ \\
\hline No symptoms & $683(5.5)$ & $2(6.1)$ & $0.703^{*}$ & $\begin{array}{l}0.90 \\
{[0.23,7.80]^{\star}}\end{array}$ \\
\hline \multicolumn{5}{|l|}{$\begin{array}{l}\text { Signs at presentation } \\
-\mathrm{n}(\%)\end{array}$} \\
\hline Respiratory signs & 10064 (81.1) & $25(75.8)$ & $0.432^{\S}$ & $\begin{array}{l}1.37 \\
{[0.62,3.05]^{\S}}\end{array}$ \\
\hline Neurological signs & $104(0.8)$ & 0 & $1^{*}$ & $\operatorname{lnf}[0.07, \operatorname{lnf}]^{*}$ \\
\hline Temperature $» 38^{\circ} \mathrm{C}$ & $3717(30.0)$ & $17(51.5)$ & $0.007 \S$ & $\begin{array}{l}0.40 \\
{[0.20,0.80]^{\S}}\end{array}$ \\
\hline No signs & $1534(12.4)$ & $4(12.1)$ & $1^{*}$ & $\begin{array}{l}1.02 \\
{[0.36,4.01]^{*}}\end{array}$ \\
\hline
\end{tabular}

The restrospective cohort of 33 patients were compared to the clinical data from a population based national data set obtained by the Belgian public health institute (Sciensano) and published in literature. (15)

$P$ values for the univariate comparison between the two groups (patients with solid cancer vs without cancer). We used a Chi-square ${ }^{\S}$ test for the categorical variables and a Fisher's exact ${ }^{\star}$ test if more than 
$20 \%$ of the expected values were lower than 5 .

OR: Odds Ratio: The corresponding odds ratio with $95 \%$ confidence interval was also calculated. For the age as continuous variable the Welch T-test ${ }^{\dagger}$ was used.

\section{Discussion}

We report on the continued Care provided in a single tertiary Cancer Center, during the first surge of the SARS-CoV-2 pandemic. As the SARS-CoV-2 pandemic spread throughout the world, it outpaced health systems everywhere. Competing with health care logistics and man power, SARS-CoV-2 challenged the Cancer Care continuum as we knew it.

Our data regarding outpatient treatments and consultations demonstrate that continued care proved feasible and safe. In order to maintain active treatment, we implemented structural changes to safeguard social distance and shorten the time spend at the Oncology out clinic. Follow up of treatment toxicity and screening for SARS-CoV-2 related symptoms was done using an modified e-tool. (23) And although both the health measures as the e-tool were well accepted; when asked if telemedicine could replace the practitioner centered health provision; only $46.2 \%$ of patients thought this could be a worthy surrogate. The latter finding might explain why we only demonstrated small differences in the in-house Oncology consults.

Telemedicine as a means to continuation of care, has been heralded as the silver lining in the cloud of the SARS-CoV-2 pandemic. (24) It is however clear that future challenges are many before it will claim its role in offering longitudinal cancer care. Going forward, technological issues will need to be addressed to allow all patients (and care providers) to navigate telemedicine; and further research will need to broaden the perspective on the preferred features of such registration and management systems (25). Hospital management will need to discuss operational issues, while support staff are engaging differently with their patients. And policy makers will need to address payment parity in order to fulfill the full potential of telemedicine. $(24,26,27)$

As in other Cancer centers we too saw a robust decline in diagnoses and appreciate the future excess in cancer morbidity (in case of stage shift, delayed treatment) and cost due to Covid-19 related disruption of care pathways. $(28,29,30,31)$

As the SARS-CoV-2 related public health and safety measures were issued, Cancer patients, in view of consensus guidelines for treatment adjustments and delays, are at greater risk of delayed cancer diagnosis and possibly postponement of curative cancer care. $(26,27,28)$

Fear, uncertainty and even mistrust towards health systems and hospitals may perhaps explain this backlog in cancer diagnoses. Adequate and timely information, an effective doctor/care team-patient relationship and prompt psychological support are critical to overcome new physical or social barriers. $(32,33)$ This can be somewhat illustrated by the results of the patient questionnaire patients' reported 
perception of organizational measures. Even though $21.9 \%$ of patients claimed to be afraid of an interaction between Cancer treatment and SARS-CoV-2 infection; over $90 \%$ felt safe (or quite safe) at the Cancer care outpatient unit. We postulate that this may be explained by the support of the care team, the information provided about and acceptance of hygienic measures ( $94.1 \%$ clear and reasonably clear).

Finally; we demonstrated a low rate of detectable SARS-CoV-2 infections in Cancer patients and compared it to a National data set by Sciensano, which included hospitalized patients; between February 15th and May 25th of 2020 (15). Although this comparison is flawed, our analysis was retrospective and limited by sample size of both in- and out-patients, we believe that presenting these real-life data illustrate the fact that Cancer patients received faster testing and screening in absence of or with a paucity of symptoms. That they suffered the same symptoms, when infected with SARS-CoV-2, but may have demonstrated an overlap with chronic underlying afflictions. Finally, that they presented earlier, as assumed by the lack of symptoms at presentation.

This study has notable limitations. We reported several retrospective cohort analyses of patient data sets retrieved from one single University Hospital site (also SARS-CoV-2 reference center); therefore, results may not be generalizable to different settings. It is also important to note that the patient questionnaire was not randomized but on a voluntary basis; the patient population may therefore be somewhat sociodemographically homogeneous: all patients spoke Dutch. (additional data)

\section{Conclusion}

COVID-19 has impacted the Clinical Cancer management in many ways; and the full extent on Care delivery remains for now largely unknown. Our report illustrates a real-life experience during the first surge of the COVID-19 pandemic in a single tertiary cancer center.

The agility and flexibility of all health care professionals to continue care in difficult circumstances is to be applauded. However, the experiences during this crisis will need to guide future Cancer Care provision.

As the SARS-CoV-2 health crisis lingers on, we must address the possible ramifications of delaying or cancelling possible curative interventions and the societal costs that will ensue. (31) Although we successfully introduced telemedicine in active cancer care and toxicity management; we need to learn from past experiences to prepare the opportunity to offer innovative state-of-the-art cancer care to patients and their caregivers from diagnosis onwards. As the benefits of collecting and addressing patient reported outcomes remotely in order to gain overall survival and reduce unplanned health care utilization are well known. $(34,35)$ Offering a broader set of (web-based or electronic) features to a multitude of stakeholders can allow telemedicine to fulfill its role in a more longitudinal Care path.

\section{Declarations}

Ethics approval and consent to participate: 
All methods were carried out in accordance with relevant guidelines and regulations. Patient registries and epidemiological data were captured in accordance to the General Data Protection Regulation (GDPR) (EU) $22016 / 679$ [21] on the protection of natural persons with regard to the processing of personal data and on the free movement of such data.

Informed consent was waived and the study protocol was approved by the medical ethics committee of the Antwerp University Hospital. (EC UZA 20/39/506; EDGE:001380). Belgian Registration number: B.3002020000180.

Consent to publication

Not applicable.

Availability of data and materials

The dataset generated and/or analysed during the current study are not publicly available due to privacy issues but are available from the corresponding author on reasonable request.

Disclosure of potential conflicts of Interest:

All author(s) indicated no potential conflict of interest.

\section{Funding}

There was no funding for the reported cohort analyses, reported in this paper.

\section{Author's Contributions}

M.R. and PVD: Conceptualization. M.R.: Data Curation, formal analysis, writing original draft, Writing review \& editing. P.V. and L.D.P.: Data Curation, Writing review \& editing. T.M. and E.C.: Resources, data curation. E.R.: Validation, Methodology Formal analysis, Writing review \& editing. S.A., A.J., P.V.D., M.P.: Writing review \& editing.

\section{Acknowledgments:}

We thank the study participants and the many physicians and nurses who reviewed, responded and interacted to symptom reports of our patients.

We also thank all medical staff members involved in the patient centered care offered in the outpatient facilities during trying times.

\section{References}

1. Petrosillo N, Viceconte G, Ergonul $O$ et al. COVID-19, SARS and MERS: are they closely related? Clin Microbiol Infect.2020; 26: 729-734. https://doi.org/10.1016/j.cmi.2020.03.026 
2. Wu F, Zhao S, Yu B et al. A new coronavirus associated with human respiratory disease in China. 2020; 579: 265-269

3. Zhou P, Yang X.L, Wang X.G et al. A pneumonia outbreak associated with a new coronavirus of probable bat origin. Nature. 2020; 579: 270-273

4. Mousavizadeh L, Ghasemi S. Genotype and phenotype of COVID-19: Their roles in pathogenesis. $J$ Microbiol Immunol infect.2020;https://doi.org/10.1016/j.jmii.2020.03.022

5. https://www.who.int/csr/don/06-november-2020-mink-associated-sars-cov2-denmark/en/

6. Liang W, Guan W, Chen R et al. Cancer patients in SARS-CoV-2 infection: a nationwide analysis in Cahina. Lancet Oncology 2020;21: 335-37.

7. Albiges L, Foulon S, Bayle A, et al. Determinants of the outcome of patients with cancer infected with SARS-CoV-2: Results from the Gustave Roussy cohort. Nature Cancer 2020;1:965-975.

8. Van Dam P, Huizing M, Mestdach G et al. SARS-CoV-2 an cancer: Are they really partners in crime? Cancer treatments reviews 2020; 89: 102068. https://doi.org/10.1016/j.ctrv.2020.102068.

9. Lee L, Cazier J-B, Starkey T et al. COVID-19 prevalence and mortality in patients with cancer and the effect of primary tumour subtype and patient demographics: a prospective cohort study. Lancet 2020; 21:1309-1316.

10. Wu Z, Mc Googan J. Characteristics of and important lessons from the Coronavirus disease 2019 (COVID-19) outbreak in China summary of a report of 72314 cases from the Chinese Center for Disease control and Prevention. Jama 2020;323 (13):1239-1242.

11. Tian J, Yuan X, Xiao J et al. Clinical characteristics and risk factors associated with COVID-A9 disease severity in patients with cancer in Wuhan, China: a multicenter, retrospective, cohort study. Lancet Oncology 2020; 21:893-903.

12. Yang $\mathrm{K}$, Sheng $\mathrm{Y}$, Huang $\mathrm{C}$ et al. Clinical characteristics, outcomes, and risk factors for mortality in patients with cancer and COVID-19 in Hubei, China: a multicentre, retrospective, cohort study. Lancet Oncol 2020;21:904-913.

13. Williamson, E. J. et al. Factors associated with COVID-19-related death using OpenSAFELY. Nature 2020; 584: 430-436. https://doi.org/10.1038/s41586-020-2521-4.

14. Tang L, Yu H. Poor clinical outcomes for patients with cancer during the COVID-19 pandemic. Lancet Oncol 2020;21: 862_863.

15. De Azambuja E, Brandão $\mathrm{M}$, Wildiers $\mathrm{H}$ et al. Impact of solid cancer on in-hospital mortality overall and among different subgroups of patient with COVID-19: a nationwide, population-based analysis. ESMO open 2020; 5:e000947. Doi:10.1136/esmoopen-2020-000947.

16. Waisberg F, Enrico D, Angel M, et al. Cancer treatment adaptations in the COVID-19 era. JCO Oncol Pract 2020; 16: 305-307.

17. Segelov $\mathrm{E}$, Underhill $\mathrm{C}$, Prenen $\mathrm{H}$, et al. Practical considerations for treating patients with cancer in the COVID-19 pandemic. JCO Oncol Pract 2020;16: 467-482.

18. https://www.esmo.org/guidelines/cancer-patient-management-during-the-covid-19-pandemic 
19. https://www.asco.org/asco-coronavirus-information

20. Marron JM, Joffe S, Jagsi R et al. Ethics and resource scarcity: ASCO recommendations for the oncology community during the COVID-19 pandemic. J Clin Oncol 2020;38/ 2201-22015.

21. https://eur-lex.europa.eu/legal-content/EN/TXT/?uri=CELEX\%3A02016R0679-20160504

22. Curigliano G, Banerjee S, Cervantes A et al. Managing cancer patients during the COVID-19 pandemic: an ESMO multidisciplinary consensus. Ann Oncol 2020; 31: 1320-1334.

23. Rasschaert M, Vanclooster PJ, Mertens T et al. The tele-transition of toxicity management in routine oncology care during the SARS-CoV-2 pandemic. Br J Cancer 2021; https://doi.org/10.1038/s41416020-01235-3

24. Patt D, Wilfong $L$, Toth $S$ et al. Telemedicine in community Cancer Care: how technology helps patients with cancer navigate a pandemic. JCP Oncology Practice 202; 17:e11-e15.

25. Haase K, Avery J, Bryant-Lukosius D et al. Patient and clinician perspectives of desired features for a web-based self-management program (icanmanage.ca): exposing patients "hard work" of managing acute cancer. Supportive Care in Cancer 2020; https://doi.org/10.1007/s00520-020-05683-8.

26. Henry BW, Block DE, Ciesla JR et al. Clinician behaviors in telehealth care delivery. Adv Health Sci Educ Theory Pract. 2017;22 (4): 869-888.

27. Shachar C, Engel J, Elwyn G et al. Implications for telehealth in a post-pandemic future Regulatory and privacy issues. JAMA 2020. doi:10.1001/jama.2020.7943

28. Sud A, Torr B, Jones ME et al. Effect of delays in the 2-week-wait cancer referral pathway during the COVID-19 pandemic on cancer survival in the UK: a modeling study. Lancet Oncol 2020; 21: 10351044.

29. Wu J, Kwon D, Glover M et al. Changes in cancer management due to COVID-19 illness in patients with cancer in Northern Carolina. JCO Oncol practice 2020; DOI https://doi.org/10.1200/OP.20.00790

30. Clark J, Dwyer D, Pinwill $\mathrm{N}$ et al. The effect of clinical decision making for initiation of systemic anticancer treatments in response to the COVID-19 pandemic I Englan: a retrospective analysis. Lancet Oncol 2021; 22:66-73.

31. COVIDsurg Collaborative. Elective surgery cancellations due to the COVID-19 pandemic: global predictive modelling to inform surgical recovery plans. BJS 2020;107: 1440-1449.

32. Curtis JR, Kross EK, Stapleton RD. The importance of addressing advance care planning and decisions about donot-resuscitate orders during novel coronavirus 2019 (COVID-19). JAMA 2020; 323(8):1771-1772.

33. Holstead RG, Robinson AG. Discussing serious news remotely: Navigating difficult conversations during a pandemic. JCO Oncology Practice 2020;16(7):363-368.

34. Denis F, Lethronsne C, Pourel N et al (2017) Randomized trial comparing a web-mediated follow-up with routine surveillance in lung cancer patients. J Natl Cancer Inst 109(9):djx029

35. Basch E, Deal A, Kris M et al (2016) Symptom monitoring with patient-reported outcomes during routine cancer treatment: A randomized controlled trial. J Clin Oncol 34(6): 557-565. 


\section{Figures}

Were the protective measures communicated?

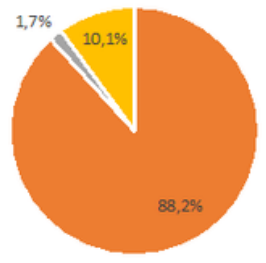

"Yes $=$ No $=$ No Opinion

Do you feel safe accessing the Oncology Unit for a cancer treatment?

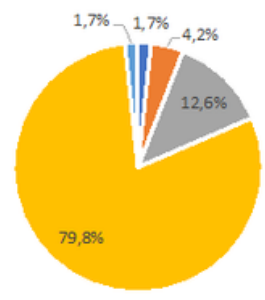

- No "NoOpinion = Quite =Yes = Missing
Are you familiar with specific risks relative to your condition?

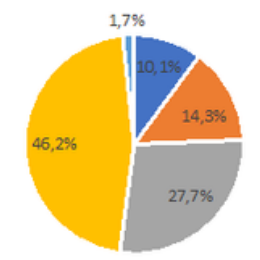

- No = A little "Q Quite = Yes = Missing

Are you afraid that cancer therapy wil infuence the SARS-CoV-2 infection rate?

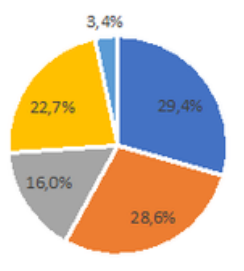

- No -A little =Quite = Yes a Missing

\section{Figure 1}

Patient questionnaire regarding knowledge and fears of COVID-19 related specific health measures, or infection risk. Answers to specific questions are indicated as percentages of total responders $(: n=119)$ Top panel refers to communication (a) and comprehension (b) of the specific measures for preventing SARS-CoV-2 infection; The bottom panel denotes distributions of relative anxiety to access the Oncology Ward (c) or receive Cancer therapy (d). SARS-CoV-2: Severe acute respiratory syndrome Coronavirus 2

\section{Supplementary Files}

This is a list of supplementary files associated with this preprint. Click to download.

- ManagementoncoBMCcancerAppendices.docx 